\title{
Usos sociais das TICs em dinâmicas de transnacionalismo e comunicação migrante em rede: uma aproximação à diáspora senegalesa no sul do Brasil
}
Social uses of ICTs in dynamics of transnationalism and network migrant communication: an approach to the Senegalese diaspora in South Brazil

Liliane Dutra Brignol ${ }^{1}$

Resumo Mesmo que as relações entre Brasil e África tenham se estabelecido em meio a muitos processos sócio-históricos, o continente ainda representa um desconhecido no contexto brasileiro. O artigo parte de uma discussão sobre os conceitos de Atlântico negro e diáspora, em sentidos mais híbridos de cultura e identidades, para pensar fluxos migratórios que reatualizam as relações entre os dois âmbitos. O texto integra pesquisa sobre comunicação e dinâmicas de migração entre Senegal e Rio Grande do Sul e tem o objetivo de explorar o processo de consumo das tecnologias da informação e comunicação por migrantes senegaleses em cidades gaúchas. A análise valoriza dois aspectos centrais assumidos pelas TICs no processo migratório: o papel de conexão transnacional e a consolidação de dinâmicas de comunicação em rede com implicações intra e interculturais.

Palavras-chave: Comunicação em rede; Usos sociais das TICs; Migração; Senegal

Abstract Although the relationships between Brazil and Africa have established among many social-historical processes, the continent still represents an unknown in the Brazilian context. The article starts from a debate on the concepts of Black Atlantic and diaspora, in more hybrid senses of culture and identities, in order to reflect upon migratory fluxes that remodel the relationships between both

\footnotetext{
1 Universidade Federal de Santa Maria - UFSM, Santa Maria, RS, Brasil.

E-mail: lilianebrignol@gmail.com
} 
realms. The text integrates research on communication and migration dynamics between Senegal and Rio Grande do Sul, and aims at exploring the consumption process of information and communication technologies by Senegalese immigrants. The analysis values two central aspects assumed by ICTs in the migratory process: the role of transnational connection and the consolidation of network communication dynamics with intra and intercultural implications.

Keywords: Network communication; Social uses of ICTs; Migration; Senegal 


\section{Introdução}

Tempo difícil para estudar o tema das migrações, das identidades em diáspora e das diversidades quando, como lembra Appadurai (2009), vivemos em uma época marcada pela violência em larga escala por motivos culturais e pelo medo em relação às minorias sociais. A guerra civil na Síria, que leva milhares de cidadãos a buscar refúgio em diferentes países, a travessia de migrantes pelo Mediterrâneo rumo à Europa, o constante debate pelo endurecimento de políticas migratórias nos países do Norte ampliam a associação da ideia de crise em relação aos movimentos migratórios.

Embora os deslocamentos entre territórios não sejam novidade na história da humanidade, e mesmo que o número absoluto dos migrantes transnacionais não tenha se alterado significativamente nos últimos anos, ${ }^{2}$ o tema das migrações contemporâneas, tratado até pouco tempo com certa invisibilidade pela mídia e pela própria sociedade brasileira, ganha outros contornos nesse início de século XXI, sobretudo pela ampliação e diversificação dos fluxos migratórios. Por aqui, também, novos sotaques ganham as ruas de grandes e pequenas cidades, chamando atenção para a diversidade e colocando em contato, de forma mais incisiva, diferenças culturais.

Ainda que a migração seja constitutiva do próprio sentido de Brasil-nação desde a colonização - com grande destaque para os deslocamentos forçados de africanos, trazidos como escravos no período colonial -, até pouco tempo, quando se falava sobre migração no contexto brasileiro, o imaginário social era alimentado por cenas de navios trazendo italianos, alemães e outros migrantes europeus inseridos em políticas de branqueamento da população em substituição ao trabalho escravo.

A chegada de migrantes provenientes de países africanos, de maioria muçulmana, jovens, negros, traz a possibilidade de convivência com outras culturas. Traz também o preconceito e o medo do outro, na reprodução de um discurso muitas vezes xenofóbico próximo do

${ }^{2}$ Em 2014, a Organização Internacional para as Migrações (OIM) estimava em 214 milhões o número de migrantes transnacionais no mundo, o equivalente a 3,1\% da população mundial. 
observado em países que convivem há mais tempo com a intensificação da presença de coletivos migrantes diversos.

Neste trabalho, ganha atenção o contexto da migração de países africanos para o Brasil, em um fluxo de deslocamento Sul-Sul (BLANCO, 2006) que marca o cenário da mobilidade humana no último período. De acordo com o Censo Demográfico 2010, o número de migrantes transnacionais residentes no Brasil aumentou 86,7\% em 10 anos. Dados do Ministério da Justiça de 2012 confirmam a intensificação da migração para o país, com o registro de 1,5 milhão de migrantes legalizados. Inúmeras razões são apontadas para esse ciclo. Entre elas, "a maior inserção do Brasil na globalização de mercado, a recente crise financeira mundial nos países desenvolvidos, o crescimento socioeconômico brasileiro e os grandes investimentos na infraestrutura da economia" (ZAMBERLAM et al., 2013, p. 17).

Entre os novos fluxos migratórios destinados ao território brasileiro, destaca-se o incremento da presença de migrantes africanos, entre eles os senegaleses. Dados da Polícia Federal (PF) divulgados pela Agência Efe de notícias apontam que, entre 2000 e 2012, o número de residentes e refugiados africanos no Brasil cresceu mais de 30 vezes, passando de 1.054 para 31.866 cidadãos africanos regularizados no país. ${ }^{3}$

Os dados são aproximativos, pela dificuldade de registro de um fluxo que, muitas vezes, não chega a compor as estatísticas oficiais. Entretanto, a presença de senegaleses já muda o cenário de diferentes locais do Brasil onde o idioma wolof passa a ser escutado entre outras tantas sonoridades urbanas. No Rio Grande do Sul, a chegada de senegaleses ganhou projeção desde 2008. Algumas cidades, sobretudo da Serra e da região Centro-norte, passaram a fazer parte do destino desses migrantes do outro lado do Atlântico, atraídos, sobretudo, pela até então crescente oferta de trabalho na indústria alimentícia, metalmecânica e na construção civil, cenário também em mudança desde 2015, com a redução de vagas no mercado de trabalho local. Destacam-se Caxias do Sul, Bento

\footnotetext{
3 Disponível em: http://oestrangeiro.org/2014/05/12/brasil-novo-destino-da-imigracao-africana/. Acesso em: 15 nov. 2015.
} 
Gonçalves, Garibaldi, Passo Fundo e, mais recentemente, Porto Alegre entre outras cidades nas quais se estima que vivam cerca de quatro mil senegaleses.

A partir desse contexto, este artigo relata parte das reflexões desenvolvidas no âmbito de projeto de pesquisa em desenvolvimento ${ }^{4}$ cujo objetivo é investigar as redes sociais migratórias desse coletivo no estado - com foco em Porto Alegre, Caxias do Sul e Passo Fundo - através de uma aproximação de caráter etnográfico a suas práticas e processos de comunicação, construídos entre usos sociais das mídias e comunicação interpessoal e intercultural.

Neste artigo, o destaque é dado para o relato das experiências de usos sociais das mídias por migrantes senegaleses, em um processo de consumo e múltiplas significações construídas pelas tecnologias da informação e comunicação (TICs). A partir do observado em pesquisas anteriores, já se sabe que os meios de comunicação, especialmente a internet e demais TICs, assumem um papel importante para a consolidação de relações transnacionais próprias das dinâmicas migratórias: possibilidade ampliada de contato entre migrantes e desses com seus familiares e amigos; construção de projetos de migração; manutenção de vínculos com o país de nascimento; aprendizado do idioma do país para o qual migraram; tomada de conhecimento e participação na cultura local; organização e mobilização social através da participação em organizações migrantes, entre outras possibilidades de usos ligadas à experiência migratória (BRIGNOL, 2010). Neste trabalho, parte-se do pressuposto de que as TICs, por suas características - como baixo custo e relativa facilidade de acesso (incluindo locais públicos e redes de conexão sem fio, por não se desconsiderar questões ligadas a desigualdades e exclusões digitais ainda existentes) -, são apropriadas de múltiplos modos pelos

\footnotetext{
${ }^{4}$ Projeto de pesquisa apoiado pela Fundação de Amparo à Pesquisa do Estado do Rio Grande do Sul - Edital FAPERGS no 02/2014, Programa Pesquisador Gaúcho - PqG. Colaboram com a pesquisa: Laura Roratto Foletto e Nathália Drey Costa, mestrandas do PPG em Comunicação da UFSM; Paola Portella de Bittencourt, bolsista de iniciação científica (Fipe UFSM); Germano Rama Molardi e Maritcheli Vieira, acadêmicos dos cursos de Comunicação Social - Jornalismo e Produção Editorial, respectivamente.
} 
migrantes como elementos de conexão transnacional e responsáveis por dinâmicas de comunicação em rede, como desenvolveremos no texto.

\section{Atlântico negro e diáspora - para entender as relações transnacionais}

Como lembra Kaly, "as migrações de africanos para o continente americano começaram no século XVI e vão se estender até o século XIX, quando se deu a abolição da escravatura” (2001, p. 110). Segundo o pesquisador, essas migrações forçadas estabeleceram uma ponte que não só encurtou as distâncias transatlânticas entre essas duas partes do planeta, mas, sobretudo, tornou suas histórias imbricadas e complementares. Apesar disso, as relações entre os dois contextos não se deram de forma contínua:

As relações entre o Brasil e boa parte da África foram estabelecidas em meio a vários processos sócio-históricos. O primeiro, que se estendeu por três séculos, foi a escravidão. O segundo começou com o retorno de alguns ex-escravos à "terra natal" ou dos antepassados - os descendentes destes são hoje encontrados com maior frequência no Benim. Depois da abolição da escravatura no Brasil, houve um hiato nas relações entre este país e a África Subsaariana. O Brasil desenvolvera e mantinha relações comerciais com os países do Norte da África e com a África do Sul. Só na década de sessenta é que a diplomacia brasileira vai mudar sua política com relação à África Negra (KALY, 2001, p. 111).

Dessa forma, mesmo que a diáspora negra seja constitutiva do próprio sentido de Brasil, mantemos, de modo geral, um profundo distanciamento com relação aos países africanos. Podemos falar em termos de um continente desconhecido, "apesar de a África ser o continente mais próximo do Brasil, de existirem imensas semelhanças humanas e naturais entre ambos, de ter havido uma forte interação ao longo da história e de os afrodescendentes constituírem cerca de um terço de nossa população" (VISENTINI, 2014, p. 11).

Esse desconhecimento dos brasileiros em relação às riquezas socioculturais, aos recursos naturais, à história, diversidade étnica e posição estratégica no mundo do continente africano é repercutido na fala de 
migrantes nascidos no Senegal e residentes no Brasil. Uma primeira aproximação, mesmo nas conversas informais realizadas na fase exploratória da pesquisa, indica certa decepção ou insatisfação diante da identificação do Senegal como “África”, percebida como um bloco monolítico e indiferenciado de países associado, na maioria das vezes, a miséria e violência. Nesse contexto, o Senegal não é a África do imaginário dos brasileiros, sobretudo porque talvez essa África não exista. Nos termos de Visentini:

A África ou a cultura africana, como totalidade histórica, não existe abstratamente em si mesma, pois representa, de certa forma, a resposta de uma criação europeia. A cultura africana constitui um movimento reativo transatlântico antiescravista e antirracista, surgido em fins do século XIX (VISENTINI, 2014, p. 11).

A ideia de uma cultura negra construída a partir da diáspora ${ }^{5}$ é desenvolvida por Gilroy (2012) ao apresentar a noção de "Atlântico negro" como formação intercultural e transnacional que rompe com paradigmas nacionalistas, contrapõe e denuncia o racismo e o etnocentrismo. A diáspora é central nessa discussão, pois aponta para um sentido mais híbrido e maleável de cultura e de identidades, sendo entendida pelo autor como uma ecologia social de identificação:

Como uma alternativa à metafísica da "raça", da nação e da cultura delimitada e codificada no corpo, a diáspora é um conceito que problematiza a mecânica cultural e histórica do pertencimento. Ela perturba o poder fundamental do território na definição da identidade ao quebrar a sequência simples de elos exploratórios entre lugar, localização e consciência (GILROY, 2007, p. 151).

\footnotetext{
${ }^{5}$ Vale ressaltar que a compreensão de diáspora no contexto do trabalho se diferencia da de migrações por entendermos o caráter mais amplo e complexo que a diáspora assume, afastando-se de seu sentido literal, ligado à ideia de dispersão forçada de povos causada por intolerância ou perseguição. As migrações representam deslocamentos próprios das dinâmicas de mobilidade humana, são um fenômeno que acompanha a história da humanidade. Em seu sentido metafórico, a diáspora permite trazer elementos para pensar sobre as identidades cada vez mais fluidas marcadas pelo jogo das diferenças, pelo confronto entre um passado imaginado e um presente cada vez mais compartilhado (HALL, 2003). Nessa perspectiva, por seu caráter transnacional e intercultural, a diáspora é pensada não apenas como sinônimo de deslocamento por diferentes territórios, mas como uma "alternativa imediata à disciplina severa do parentesco primordial e do pertencimento enraizado” (GILROY, 2007, p. 151).
} 
Hall também reflete sobre uma ampliação do conceito de diáspora, em um processo que não se apoia em uma concepção binária da diferença, mas requer, nas palavras do autor, "fronteiras veladas que não separam finalmente, mas são também places de passage, e significados que são posicionais e relacionais, sempre em deslize ao longo de um espectro sem começo nem fim" (HALL, 2003, p. 33). Ao falar sobre a diáspora caribenha, o autor destaca, mais uma vez, o caráter híbrido de suas rotas: "Sabemos que o termo 'África' é, em todo o caso, uma construção moderna, que se refere a uma variedade de povos, tribos, culturas, línguas cujo principal ponto de origem comum situa-se no tráfico de escravos" (HALL, 2003, p. 31).

Da mesma forma, Gilroy pensa o Atlântico negro não em termos de uma unidade cultural garantida por uma herança africana comum, mas como uma multiplicidade de experiências transnacionais e interculturais. Nesse processo, a questão colonial pode ser pensada como um dos aspectos de convergência, implicando a experiência compartilhada da escravidão, da discriminação racial e da ascensão de uma consciência nacional impregnada de negação do próprio colonialismo (GILROY, 2012, p. 365).

\section{Redes migratórias entre Brasil e Senegal}

A diáspora também é importante na constituição do Senegal. O país, localizado na África Ocidental, colônia francesa até 1960, tem sua história marcada pela trajetória de deslocamento de sua população, sobretudo rumo à França e a outros países da Europa, como Espanha e Itália, e depois aos Estados Unidos, identificados como sinônimo de progresso. Desde o começo do século XXI, com o endurecimento de políticas migratórias, vêm-se diversificando os destinos, sendo a América do Sul, principalmente Argentina e Brasil, os mais frequentes.

Segundo Dialo (2011, p. 18), a República do Senegal, que antes fazia parte da Senegâmbia, é considerada referência, no continente africano, na questão da democracia, “com uma preservação democrática do sistema multipartidário desde a independência e criação efetiva de um 
Estado considerado forte devido à consolidação das instituições que legitimam o monopólio do uso da força em todo o seu território".

Apesar de um conflito localizado na região da Casamance, entre Gâmbia e Guiné Bissau, que se estende desde 1981, esse não parece ser o principal motivo da migração. Kleidermacher (2013) analisa o contexto das migrações de senegaleses para a Argentina desde os anos $1990 \mathrm{e}$ explica que, durante o século XX, os deslocamentos foram estimulados fundamentalmente por ação colonizadora francesa. "Durante este período, la administración colonial enviaba a la metrópoli a civilizar a las elites senegalesas colaboracionistas, lo que generaba en la población la imagen de que la riqueza y el poder había que buscarlos fuera de Senegal" (KLEIDERMACHER, 2013, p. 112).

A presença de projetos migratórios como parte das trajetórias pessoais dos senegaleses residentes em Buenos Aires é marcante na análise de Kleidermacher (2013). O mesmo é percebido entre os relatos dos entrevistados no sul do Brasil: entre as motivações para migrar aparecem a busca por melhores condições de trabalho e a possibilidade de envio de dinheiro para parentes no Senegal, em dinâmicas de famílias ampliadas com as quais são reconfigurados vínculos no contexto transnacional.

O Brasil, no entanto, nem sempre surge como primeira opção entre os migrantes contatados na pesquisa. Alguns deles destacaram a relação com parentes e amigos residentes nos Estados Unidos e na Espanha, mas comentaram sobre a dificuldade atual de entrada nesses países. O contato inicial com outros senegaleses no Brasil, através da consolidação de redes de apoio, é o ponto em comum entre as experiências dos entrevistados. Essas redes (informais, mas que consolidam também associações organizadas) guardam relação com laços comunitários e religiosos construídos entre os migrantes, de maioria muçulmana, e articulados em irmandades religiosas ligadas à ordem islâmica "Mouride". 6

\footnotetext{
${ }^{6}$ Segundo Moreno Maestro (2006 apud Kleidermacher, 2013), a irmandade Mouride é majoritária no Senegal e foi fundada por Cheikh Ahmadou Bamba no final do século XIX. Tem inspiração sufí e seu centro religioso se encontra na cidade santa de Touba.
} 
Ainda em análise no contexto argentino, Chevalier-Beaumel e Morales (2012) lançam um olhar sobre o que definem como a produção de saberes singulares (um savoir migrer) ancorada em redes sociais - não apenas religiosas, mas de parentesco, amizade, étnicas e laborais - essenciais para a compreensão das dinâmicas migratórias e das relações transnacionais experimentadas.

As redes, orientadas em termos de fatores como localização, regionalização, amizade e conhecimento mútuo, são entendidas também como canais que produzem e alimentam os fluxos migratórios por Tedesco e Grzybovski (2013), em análise sobre a dinâmica migratória no norte do Rio Grande do Sul a partir de dados de pesquisa exploratória realizada em Passo Fundo entre 2009 e 2011. Os pesquisadores identificam um perfil migrante formado por uma maioria de homens entre 25 e 40 anos oriundos de pequenas cidades do Senegal, além da capital Dakar, que passaram a ocupar postos de trabalho principalmente em abatedouros de aves e na construção civil.

A lógica de redes é percebida como um movimento associado ao processo de migração (PASCUAL DE SANS, 2007), sendo observada desde a construção do projeto migratório, ou seja, na decisão de migrar incentivada pelo exemplo e estímulo de parentes, amigos e conhecidos que já passaram pela experiência. As redes migratórias, pelo que diferentes investigações apontam, estão presentes também na articulação de interações que atuam no processo de instalação no país de migração e na manutenção de vínculos com o país de nascimento, por meio do contato com migrantes da mesma nacionalidade e participação em ambientes de convívio comuns.

\section{Perspectiva etnográfica para aproximação às redes migratórias de senegaleses}

A etnografia, em sua tripla acepção como enfoque, método e texto (GUBER, 2001), vem sendo adotada como perspectiva importante no campo do estudo das migrações contemporâneas. Neste trabalho, busca-se uma 
aproximação às redes migratórias de senegaleses através de uma combinação de procedimentos menos diretivos e que procuram incluir a reflexividade dos pesquisadores de modo a aliar observação prolongada e escuta de relatos dos sujeitos pesquisados.

Como aponta Guber (2001), a etnografia reúne um conjunto de atividades de "trabalho de campo" cujo resultado se emprega como evidência para a descrição e a interpretação. É um método aberto de investigação que combina, prioritariamente, a observação participante e as entrevistas não dirigidas aliadas a uma aproximação prolongada aos sujeitos que compõem o estudo, lembrando que a investigação não se faz sobre um grupo social, mas com e a partir dele.

Como recorte para o trabalho de campo, buscamos conhecer, por meio das técnicas da observação simples, observação participante, conversas informais e entrevistas semiestruturadas (GIL, 2008), o contexto das redes sociais migratórias de senegaleses no Rio Grande do Sul. A observação simples e a observação participante partem da aproximação às entidades de apoio às migrações no estado, além das próprias associações e entidades migrantes. ${ }^{7}$

A opção pela etnografia nos leva também a uma escrita mais livre e interpretativa em busca de uma aproximação à complexidade do contexto social, cultural e de múltiplas imbricações identitárias construídas na relação entre Brasil e Senegal no contexto das migrações. Ao longo do processo de observação, procuramos conhecer as dinâmicas de redes de migrantes senegaleses em suas práticas associativas, como reuniões, encontros, mobilizações, festas, atividades religiosas. Esse processo se dá tanto pelo acompanhamento de atividades presenciais ligadas à diáspora senegalesa quanto por meio das redes sociais on-line, em páginas,

\footnotetext{
O associativismo é uma prática, em muitos casos, ligada ao fenômeno migratório. As associações (assim como clubes, ONGs, grupos culturais, movimentos sociais, entidades confessionais etc.) atuam como parte das redes de apoio à migração nos contextos para os quais migraram e integram movimentos coletivos de caráter diverso em torno da experiência migratória. Uma categorização de tipologias de associações migratórias é recuperada por Cogo (2012) com base em outros trabalhos. No caso dos senegaleses, identificamos associações nas cidades de Caxias do Sul, Porto Alegre e Passo Fundo, além de uma em processo de organização em Rio Grande. Todas foram criadas e são geridas pelos próprios migrantes.
} 
comunidades e perfis no Facebook, por exemplo, através dos quais podemos acompanhar e participar de ações organizadas pelos coletivos, além de fazer um contato inicial com os próprios migrantes.

No estágio atual da pesquisa, além de conversas informais, foram realizadas seis entrevistas semiestruturadas a partir de um roteiro de aproximação que se propõe a conhecer, por meio das narrativas dos migrantes, questões relacionadas a usos sociais das mídias e dinâmicas de comunicação em rede em suas relações com aspectos identitários e de interculturalidade (GRIMSON, 2001). Entre os entrevistados, há líderes e coordenadores das associações formais e também das dinâmicas em rede informais, além de migrantes com perfis e trajetórias de migração distintas (quanto a idade, nível de escolaridade, atividades profissionais e tempo de migração).

Quanto à observação e às conversas informais, são feitas no contexto das cidades com presença do coletivo, sobretudo Caxias do Sul e Porto Alegre, e em atividades promovidas pelos próprios coletivos migrantes, como em reunião da Associação dos Senegaleses de Porto Alegre, em junho de 2015, e no $1^{\circ}$ Baile Senegalês, promovido pela Associação dos Senegaleses de Caxias do Sul em agosto de 2015.

\section{Usos sociais das TICs em dinâmicas transnacionais e de comunicação em rede}

Em nossa pesquisa, sobretudo por meio da observação participante em atividades organizadas por senegaleses, das conversas informais e das entrevistas, identificamos um perfil de sujeitos jovens, entre 20 e 30 anos, na maioria homens e com escolaridade variada - alguns com graduação completa, outros com o equivalente ao ensino médio ou técnico no Senegal. Nas dinâmicas observadas, encontramos apenas cinco mulheres senegalesas.

O wolof é o principal idioma falado, usado nas reuniões e nas conversas entre os senegaleses, por exemplo, embora alguns falem também o francês, língua oficial do Senegal, e o árabe. Um conhecimento inicial 
de espanhol ajudou alguns migrantes a aprender o português, falado sem dificuldades pelos senegaleses há mais tempo no país, mas ainda um problema para a comunicação dos migrantes mais recentes, que precisam contar com a ajuda de intérpretes entre os próprios conhecidos.

Todos os migrantes com quem conversamos são muçulmanos e participam de encontros e atividades religiosas nas cidades estudadas. Em Caxias do Sul, além de atuar na associação, os migrantes participam da Dahira, associação religiosa ligada à rede Mouride que funciona em casa alugada no centro da cidade. A chegada ao estado intensificou-se desde o ano de 2008, mas também observamos alguns recém-chegados - parte dos quais entrou no Brasil pelo Acre, vindos do Equador, enquanto outros chegaram de avião a São Paulo e prosseguiram de ônibus até o Rio Grande do Sul.

A inserção profissional vem mudando nos últimos anos: com demissões em empresas alimentícias e do setor metalmecânico, muitos migrantes atuam no comércio informal, vendendo produtos como bijuterias, relógios e roupas nas ruas centrais das cidades. Outros combinam um emprego formal, de carteira assinada, com a atuação no comércio de rua como forma de ampliar a renda ou, ainda, abrem seus próprios negócios no ramo da prestação de serviços. Entre os seis entrevistados, identificamos um mecânico (também vendedor ambulante nos finais de semana, atividade em que o encontramos no parque da Redenção, em Porto Alegre), um empregado no ramo da produção em frigorífico na região metropolitana de Porto Alegre, um vendedor ambulante que estuda em curso técnico de Administração no turno da noite, um pintor e dois empresários, ambos em Caxias - o primeiro é dono de uma empresa de telefonia para chamadas internacionais e o segundo, com atuação no ramo do design gráfico no Senegal, abriu sua própria gráfica.

As associações de migrantes ocupam um lugar central na dinâmica migratória nos contextos estudados. Como parte das redes de apoio, as associações atuam na organização migrante, na acolhida aos recém-chegados, na organização para a busca de emprego e moradia (na maioria das vezes, compartilhada com outros senegaleses), na ajuda diante das 
dificuldades com o idioma ou no percurso em busca da regularização da situação jurídica no país. São também espaços de sociabilidade e de reconhecimento na diáspora, além de atuar em atividades culturais de aproximação com as comunidades locais.

Fundada em 2013, a Associação dos Senegaleses de Caxias do Sul promoveu em 2015, por exemplo, uma participação na tradicional romaria de Nossa Senhora de Caravaggio, com cerca de 30 senegaleses percorrendo mais de 20 quilômetros entre Caxias do Sul e o município de Farroupilha com uma mensagem de paz e de aproximação entre as religiões. O Baile Senegalês, realizado no ponto de cultura da União das Associações de Bairros de Caxias do Sul, buscava, além da promoção do encontro para vivência cultural através da música e da dança, angariar fundos para custear gastos com a casa alugada pela associação para os migrantes recém-chegados.

Em Porto Alegre, segundo seu presidente, o principal objetivo da associação é a união dos senegaleses, a discussão das principais demandas e dificuldades na cidade, assim como atuar contra preconceitos com relação aos migrantes. Uma reportagem no Jornal do Almoço, da RBS TV, afiliada da Rede Globo de Televisão, com entrevistas a migrantes, entre eles o próprio presidente da associação, veiculada em junho de 2015 foi comemorada como uma oportunidade de mostrar aos gaúchos um pouco do cotidiano e da cultura dos senegaleses, de modo a buscar romper com estereótipos que ainda prevalecem (reforçados, muitas vezes, também na cobertura da mídia sobre o tema das migrações).

Nesse contexto de consolidação de redes migratórias e da organização de entidades de caráter associativo, cultural e religioso, as TICs assumem um caráter essencial de articulação dos senegaleses. A abordagem dos usos sociais das mídias - perspectiva vinculada aos estudos culturais latino-americanos (MARTÍN-BARBERO, 2002) - ajuda a construir o percurso teórico-metodológico do trabalho, no qual a análise se volta a práticas sociais de múltiplas apropriações e ressignificações no processo sempre mediado de relação com as mídias. 
Em nossa observação, ganhou projeção o uso do telefone celular como meio mais importante para a comunicação dos migrantes. Entre os entrevistados, mesmo que três deles relatem possuir computador, as tecnologias móveis garantem a principal forma de acesso à internet. Todos destacaram a importância de chegar ao país e comprar um chip de uma operadora de telefonia local. Um deles enfatizou, ainda, ao mostrar o aparelho, que tinha sido seu primeiro objeto adquirido no Brasil, como presente de um amigo, seu único contato no país antes de migrar. Os relatos indicam, ainda, o uso de diferentes operadoras como forma de aproveitar promoções e baratear os custos com as ligações. Ao solicitar o número do telefone dos entrevistados para contatos futuros, vários foram os momentos em que fomos questionados sobre nosso número e sobre qual era a operadora para registro na lista de contatos do aparelho.

Aliado ao acesso à internet $3 \mathrm{G}$, o celular oferece possibilidade de conexão constante e comunicação facilitada com parentes e amigos. Para isso, os aplicativos de mensagens instantâneas e que permitem chamadas telefônicas gratuitas, como WhatsApp, Viber e Imo, são fundamentais. Trata-se, pelo que observamos, da principal forma de manutenção de contato de quem está no Brasil com familiares no Senegal.

Nas atividades das associações em que estivemos presentes, o celular, quase sempre um smartphone com muitos recursos, ainda era usado para a produção de fotos e vídeos que logo eram postados em sites de redes sociais, principalmente no Facebook. Também observamos o registro de selfies, imagens de si mesmo, compartilhadas nesses sites, entendidos, nesse contexto, como ambientes de comunicação e sociabilidade de importância crescente entre os migrantes.

Além dos perfis pessoais, o site de rede social Facebook é apropriado através do recurso das páginas, que permitem o gerenciamento e compartilhamento de conteúdo entre aqueles que as seguem. Em nossa observação, as associações migrantes ganham visibilidade e divulgam suas ações nessas páginas, criadas e geridas pelos próprios senegaleses. De modo geral, com conteúdo em wolof e francês e algumas vezes traduzido para o português, as páginas chamam para as atividades das 
associações, compartilham fotos e vídeos dessas ações, divulgam temas de interesse dos migrantes e fazem circular matérias publicadas na mídia local e nacional sobre a temática da migração senegalesa. Em alguns momentos, pudemos identificar referências contra o preconceito racial, mensagens sobre a integração entre Brasil e Senegal e em favor da valorização da cultura senegalesa.

Outro espaço de observação da pesquisa é a loja de serviços de telefonia de um dos entrevistados, figura central na dinâmica migratória no contexto gaúcho por ocupar também o papel de presidente da Associação dos Senegaleses de Caxias do Sul, com forte atuação em rede com outras associações e entidades de apoio às migrações. A loja está localizada em uma galeria comercial no centro da cidade e é apropriada, em termos que podemos aproximar aos de Peñaranda Cólera (2005), como espaço social transnacional onde, mais do que acesso a TICs a baixo custo, são consolidadas dinâmicas de redes sociais entre as comunidades migrantes e dessas com seus países de nascimento através da mediação tecnológica. Ali encontramos, além de cabides para chamadas telefônicas internacionais e nacionais, anúncios para locação de quartos em moradias compartilhadas, cartazes e imagens que remetem à cultura senegalesa e à religião muçulmana e roupas típicas para venda entre os senegaleses. O ambiente funciona também como ponto de encontro dos migrantes.

A partir dessas aproximações iniciais, destacamos dois eixos centrais para pensarmos o consumo das tecnologias pelos migrantes senegaleses. No primeiro deles, ganha relevância a apropriação das TICs para a manutenção de vínculos com o país de nascimento e com locais de residência de parentes e amigos migrantes.

Como propõe Portes (2004, p. 74), o transnacionalismo é uma perspectiva nova, mas não um fenômeno novo para se pensar sobre as práticas migratórias. Sem dúvida, como alerta o autor, embora as relações entre país de nascimento e de migração sempre tenham existido, a emergência de tecnologias tanto de transporte quanto de telecomunicações facilita a comunicação rápida, que atravessa as fronteiras nacionais. 
Como parte da dinâmica migratória, o acesso e o domínio do uso de TICs, centralizadas agora no telefone celular, permitem a configuração de relações transnacionais que conferem muito mais do que o envio de remessas econômicas dos migrantes para o Senegal. Os laços transnacionais passam também pelas relações afetivas, familiares e de parentesco. No caso das famílias transnacionais, encontramos, por exemplo, o relato de dois migrantes casados com mulheres residentes no Senegal. Um deles, inclusive, embora já conhecesse a mulher há muitos anos, não a via desde o casamento, mas mantinha comunicação constante através das trocas de mensagens instantâneas e das ligações por aplicativos para smartphone.

As relações transnacionais também acionam questões culturais e, no que estamos percebendo entre a comunidade senegalesa, principalmente religiosas. O estabelecimento de associações articuladas em torno da religião muçulmana e da irmandade Mouride é um dos aspectos que merece atenção para entender a organização das redes migratórias senegalesas concentradas em algumas cidades. Através dessa organização são mantidas as práticas de leitura do Alcorão e a celebração de datas religiosas, assim como já houve a visita de líderes do Senegal a atividades religiosas promovidas na cidade de Caxias do Sul, por exemplo.

Como segundo eixo da análise, destacamos que as dinâmicas migratórias são organizadas em torno de redes sociais de apoio, para as quais a mediação tecnológica promove uma articulação muito importante. As lógicas de comunicação em rede, articuladas entre a comunicação interpessoal não mediada e múltiplas apropriações das TICs, reconfiguram a experiência de deslocamento e ampliam as possibilidades de conexão entre os próprios migrantes.

O espaço da loja de telefonia como ambiente de caráter transnacional é um sinalizador importante para a relevância da comunicação entre os senegaleses e deles com suas famílias e amigos residentes no Senegal. As TICs também são apropriadas para a organização das associações, aproximando, como podemos observar, as entidades de caráter organizativo e de reconhecimento. No trabalho de campo, por exemplo, tomamos 
conhecimento de um grupo no aplicativo WhatsApp compartilhado por líderes das associações de diferentes cidades brasileiras e usado para facilitar a comunicação e o planejamento de ações entre os migrantes.

A comunicação em rede assume também uma função importante no processo de aproximação entre as culturas migrantes e as comunidades locais nas cidades com forte presença senegalesa. Assim, as páginas e os grupos em sites de redes sociais tornam-se espaços de divulgação de aspectos pouco abordados sobre a cultura senegalesa e as contribuições dos coletivos migrantes nas cidades gaúchas. Servem, ainda, para compartilhar as informações publicadas na mídia local, além de promover a mobilização e a aproximação entre os migrantes e, de forma ainda inicial, as comunidades locais.

\section{Considerações finais}

O estudo das lógicas de comunicação em redes migratórias em um contexto de mudanças do próprio fenômeno das migrações no âmbito brasileiro traz novas percepções sobre relações entre mídias, redes e identidades. Neste artigo, a partir de uma aproximação analítica aos usos sociais das TICs em dinâmicas de comunicação por migrantes senegaleses no Rio Grande do Sul, são analisados elementos que ajudam a compreender um cenário de novas articulações entre o Brasil e o continente africano, unidos por uma série de relações sócio-históricas - entre elas, a própria experiência do colonialismo e da diáspora como constitutivos de culturas e identidades em constantes transformações.

Nesse percurso, destacamos o papel das TICs para organização das lógicas de comunicação em rede entre os migrantes. As tecnologias móveis, através dos usos do telefone celular aliado à internet $3 \mathrm{G}$ ou por conexão sem fio, ganham relevância como principal meio de comunicação entre os migrantes. A manutenção de vínculos com familiares, o envio de remessas financeiras, a busca de informações para o projeto de migração, a consolidação de práticas comunicativas em redes de apoio ao fenômeno migratório e a articulação de organizações de caráter 
associativo, cultural e religioso aparecem como sentidos comuns na relação dos senegaleses com as tecnologias.

A partir desses usos sociais das TICs, a consolidação de relações transnacionais e dinâmicas de redes entre os migrantes integra um processo mais amplo de novos ordenamentos dos fluxos migratórios transnacionais, em que o Brasil se destaca como país de migração para coletivos diversos daqueles que, já há mais tempo, constituem a sua população. Dessa forma, conseguimos indicar alguns percursos através dos quais se constituem relações transnacionais entre o Brasil e o Senegal em práticas de interação e comunicação mediadas por múltiplas apropriações das TICs entre os próprios sujeitos migrantes, entre eles e sua rede familiar no Senegal e entre os coletivos e a comunidade local.

No caso da migração senegalesa, o desconhecimento sobre o Senegal e suas culturas, a diferença de idiomas, a questão religiosa e de identidade étnica podem levar a situações de preconceito e xenofobia. Nesse sentido, as redes de apoio construídas em torno da questão religiosa e de associações culturais mediadas por distintas apropriações das TICs, como analisamos, tornam-se importantes na dinâmica migratória, sobretudo por permitir a aproximação e a colaboração entre os migrantes e o reforço de vínculos com as identidades e culturas do Senegal, além de dar visibilidade às dificuldades no âmbito da experiência migratória e às disputas por políticas de reconhecimento migrante.

A análise da migração senegalesa sob o viés dos sujeitos em suas múltiplas trajetórias permite apontar o papel articulador das TICs. Mais do que integrar suas dinâmicas, a comunicação em rede é constitutiva da própria experiência migratória, implicando o caráter dinâmico e complexo de uma diáspora que se constrói a partir de experiências transnacionais atravessadas pela mediação tecnológica. 


\section{Referências}

APPADURAI, A. O medo ao pequeno número: ensaio sobre a geografia da raiva. São Paulo: Iluminuras: Itaú Cultural, 2009.

BLANCO, C. Migraciones: nuevas movilidades en un mundo en movimiento. Barcelona: Anthropos, 2006.

BRIGNOL, L. D. Migrações transnacionais e usos sociais da internet: identidades e cidadania na diáspora latino-americana. 2010. Tese (doutorado em Ciências da Comunicação) - Programa de Pós-graduação em Ciências da Comunicação, Universidade do Vale do Rio dos Sinos, São Leopoldo, RS, 2010.

CHEVALIER-BEAUMEL, E; MORALES, O. G. Aproximación etnográfica a la nueva migración africana em Argentina. Circulación y saberes en el caso de los senegaleses arribados em las últimas dos décadas. Astrolabio, v. 1, n. 8, p. 381-405, 2012.

COGO, D. Latino-americanos em diáspora: usos de mídias e cidadania das migrações transnacionais. Rio de Janeiro: Tríbia, 2012.

DIALO, M. A. A construção do estado do Senegal e integração na África Ocidental: Os problemas da Gâmbia, de Casamance e da integração regional. 2011. 186f. Dissertação (mestrado em Ciência Política) - Programa de Pós-graduação em Ciência Política, Universidade Federal do Rio Grande do Sul, Porto Alegre, 2011.

GIL, A. C. Métodos e técnicas de pesquisa social. São Paulo: Atlas, 2008.

GILROY, P. Entre campos: nações, culturas e o fascínio da raça. São Paulo: Annablume, 2007.

GILROY, P. O Atlântico Negro: modernidade e dupla consciência. São Paulo: Editora 34, 2012.

GRIMSON, A. Comunicación y interculturalidad. Colômbia: Grupo Editorial Norma, 2001.

GUBER, R. La etnografía: método, campo y reflexividad. Buenos Aires: Grupo Editorial Norma, 2001.

HALL, S. Da diáspora: identidades e mediações culturais. Belo Horizonte: Unesco, 2003.

KALY, A. P. O Ser Preto africano no "paraíso terrestre" brasileiro: um sociólogo senegalês no Brasil. Lusotopie, Bordeaux, França, p. 105-121, 2001. Disponível em: http:// www.lusotopie.sciencespobordeaux.fr/kaly.pdf. Acesso em: 24 maio 2015.

KLEIDERMACHER, G. Entre cofradías y venta ambulante: una caracterización de la inmigración senegalesa en Buenos Aires. Cuadernos de Antropología Social, v. 1, n. 38, p. 109-130, 2013.

MARTÍN-BARBERO, J. Oficio de cartógrafo: travesías latinoamericanas de la comunicación en la cultura. Santiago de Chile: Fondo de Cultura Económica, 2002.

PASCUAL DE SANS, A. (Dir.). Redes sociales de apoyo: la inserción de la población extranjera. Bilbao, Espanha: Fundación BBVA, 2007.

PEÑARANDA CÓLERA, M. C. El locutorio como espacio social transnacional: una mirada psicosocial. Athenea digital. Revista de pensamiento e investigación social, n. 
8, p. 454-460, 2005. Disponível em: http://atheneadigital.net/ojs-athenea/athenea/issue/ view/9. Acesso em: 12 abr. 2014.

PORTES, A. Convergências teóricas e dados empíricos no estudo do transnacionalismo imigrante. Revista Crítica de Ciências Sociais, n. 69, p. 73-93, 2004. Disponível em: http://dialnet.unirioja.es/servlet/articulo?codigo=1288934. Acesso em: 04 nov. 2014.

TEDESCO, J. C.; GRZYBOVSKI, D. Dinâmica migratória dos senegaleses no norte do Rio Grande do Sul. Revista Brasileira de Estudos Populacionais, v. 30, n. 1, p. 317-324, 2013.

VISENTINI, P. F; RIBEIRO, L. D.; PEREIRA, A. D. História da África e dos africanos. Petrópolis: Vozes, 2014.

ZAMBERLAM, Jurandir; BOCHI, Lauro; CORSO, Giovani; CIMADON, João Marcos. Imigrante: a fronteira da documentação e o difícil acesso às políticas públicas em Porto Alegre. Porto Alegre: Solidus, 2013.

Data de submissão: 25/08/2015

Data de aceite: 20/11/2015 